\title{
Architecture_MPS
}

\section{Not in my City: Rural America as Urban Dumping Ground}

Forbes Lipschitz ${ }^{1}$

How to cite: Lipschitz, F. 'Not in my City: Rural America as Urban Dumping Ground.' Architecture_MPS, 2014, 6(1): 2, pp. 1-19. DOI:

https://doi.org/10.14324/111.444.amps.2014v6i2.001.

Published: 01 December 2014

\section{Peer Review:}

This article has been peer reviewed through the journal's standard Editorial double blind peer review.

\section{Copyright:}

(C) 2014, The Author(s). This is an Open Access article distributed under the terms of the Creative Commons Attribution License (CC-BY) 2.0 https://creativecommons.org/licenses/by/2.0/, which permits re-use, distribution and reproduction in any medium, provided the original author and source are credited • DOI: https://doi.org/10.14324/111.444.amps.2014v6i2.001

\section{Open Access:}

Architecture_MPS is a peer-reviewed open access journal.

\footnotetext{
${ }^{1}$ Robert Reich School of Landscape Architecture, Louisiana State University, USA
} 


\title{
Title: Not in my City: Rural America as Urban Dumping Ground
}

\author{
Forbes Lipschitz
}

Architecture_media_politics_society. vol.6, no.2.

December 2014

Affiliation: Robert Reich School of Landscape Architecture, Louisiana State University

\begin{abstract}
:
The ideological divide between "urban" and "rural" is deeply rooted in the American consciousness, fraught with tensions stemming from false memories of a pastoral past on the one hand and the American yearning for progress as exemplified by the industry of the city on the other. These tensions have figured prominently in design discourse, from Ebenezer Howard's Garden City to Patrick Geddes Rural-to-Urban Transect and Ian McHarg's Design with Nature. Over the last twenty years, however, rural issues have been wholly overshadowed by design's fixation on urbanization. Though urban design and planning are well established subdisciplines of the design professions, rural issues receive limited pedagogical or practical emphasis. Across design disciplines, the contemporary city is touted as the key to technological, economic and cultural innovation while rural decline is accepted as inevitable, if not necessary.

This resignation to the eventuality of rural decline has facilitated an exploitative relationship between urban hubs and their rural hinterlands. Rural America — which encompasses roughly seventy-two percent of the nation's landmass - has seen slower population growth for a decade as more young people move to urban and suburban areas for jobs and aging retirees seek out more densely populated places to live. The 2010 census revealed that nonmetropolitan counties officially lost population for the first time. The economic landscape of rural America is also in a state of flux. Rural areas have traditionally relied upon resource-extractive industries, such as agriculture, forestry and energy production. However, technological advances, outsourcing, and the decline of manufacturing have forced rural communities to reevaluate their local economies. Declining populations coupled with limited economic opportunities characterize a number of rural communities across the United States. Looking for stable economic investments, policy makers and officials in rural areas across the country actively court landfills, prisons, and meat production and processing facilities in hopes of creating new jobs and generating revenue for towns in need of economic revitalization.
\end{abstract}




\section{Amps}

In the United States, Locally Undesirable Land Uses (LULUs) are increasingly being pushed out of cities and into rural areas. Though most city dwellers would agree that LULUs like power plants, factories, and hazardous waste storage facilities are necessary, most would prefer not to live near them. Though LULUs may offer significant benefits to society at large, they do so at the expense of neighboring communities. The siting of such unsavory land uses also typically exploits disadvantaged and unempowered populations and makes the rural-dumping ground paradigm particularly problematic. While the economic benefits of LULUs are largely unproven, the negative environmental and social consequences can be wide ranging. Landfills and livestock operations, for example, pollute land, air, and water resources, negatively impacting biodiversity and public health. As an out-of-sight-out-of-mind strategy, the geographic displacement of these ecologically and socially damaging systems enables relocation over reformation. By analyzing the geography and design of three of the most significant LULUs, meat production and processing facilities, landfills, and prison complexes, this study seeks to illuminate the extent to which unwanted urban land uses are impacting rural areas today. 


\title{
Title: Not in My City: Rural America as Urban Dumping Ground
}

\author{
Authors: Forbes Lipschitz
}

\section{Architecture_media_politics_society.vol.6, no.2.}

December 2014

\section{Introduction}

The ideological divide between "urban" and "rural" is deeply rooted in the American consciousness, fraught with tensions stemming from false memories of a pastoral past on the one hand and the American yearning for progress as exemplified by the industry of the city on the other. These tensions have figured prominently in design discourse, from Ebenezer Howard's Garden City ${ }^{1}$ to Patrick Geddes Rural-to-Urban Transect ${ }^{2}$ and Ian McHarg's Design with Nature. ${ }^{3}$ Over the last twenty years, however, rural issues have been wholly overshadowed by design's fixation on urbanization. Though urban design and planning are well established subdisciplines of the design professions, rural issues receive limited pedagogical or practical emphasis. Across design disciplines, the contemporary city is touted as the key to technological, economic and cultural innovation while rural decline is accepted as inevitable, if not necessary.

This resignation to the eventuality of rural decline has facilitated an exploitative relationship between urban hubs and their rural hinterlands. ${ }^{4}$ Rural America — which encompasses roughly seventy-two percent of the nation's landmass - has seen slower population growth for a decade as more young people move to urban and suburban areas for jobs and aging retirees seek out more densely populated places to live. ${ }^{5}$ The 2010 census revealed that non-metropolitan counties officially lost population for the first time. ${ }^{6}$ The economic landscape of rural America is also in a state of flux. Rural areas have traditionally relied upon resource-extractive industries, such as agriculture, forestry and energy production. However, technological advances, outsourcing, and the decline of manufacturing have forced rural communities to reevaluate their local economies. Declining populations coupled with limited economic opportunities characterize a number of rural communities across the United States. Looking for stable economic investments, policy makers and officials in rural areas across the country 


\section{Amps}

actively court landfills, prisons, and meat production and processing facilities in hopes of creating new jobs and generating revenue for towns in need of economic revitalization.

In the United States, Locally Undesirable Land Uses (LULUs) are increasingly being pushed out of cities and into rural areas. Though most city dwellers would agree that LULUs like power plants, factories, and hazardous waste storage facilities are necessary, most would prefer not to live near them. Though LULUs may offer significant benefits to society at large, they do so at the expense of neighboring communities. The siting of such unsavory land uses also typically exploits disadvantaged and unempowered populations and makes the rural-dumping ground paradigm particularly problematic. While the economic benefits of LULUs are largely unproven, the negative environmental and social consequences can be wide ranging. Landfills and livestock operations, for example, pollute land, air, and water resources, negatively impacting biodiversity and public health. As an out-of-sight-out-of-mind strategy, the geographic displacement of these ecologically and socially damaging systems enables relocation over reformation. By analyzing the geography and design of three of the most significant LULUs, meat production and processing facilities, landfills, and prison complexes, this study seeks to illuminate the extent to which unwanted urban land uses are impacting rural areas today.

\section{Rural Livestock Production and Processing}

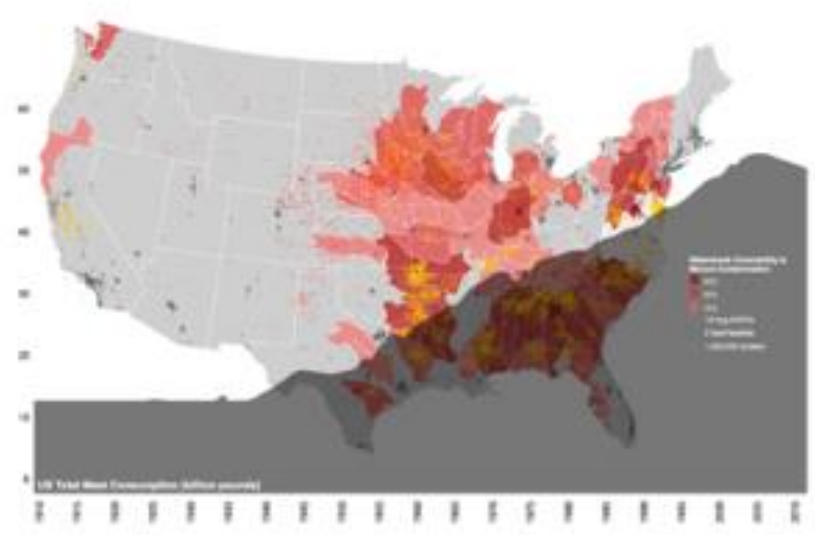

Figure 1. Mapping livestock production, meat consumption and watershed contamination ${ }^{7}$

At the turn of the $20^{\text {th }}$ century, slaughterhouses were common fixtures of the urban landscape. Cattle and hogs were transported by rail to stockyards in Chicago, Cincinnati, St. Louis and Kansas 


\section{Amps}

City, where they could be processed and distributed to nearby markets. ${ }^{8}$ In response to national trends of urbanization and industrialization, animal processing emerged as one of the first mass-production industries in the United States, from which Henry Ford is thought to have derived his mode of assembly line production. Slaughterhouses were not hidden from the public eye, but rather celebrated as icons of progress and innovation. In fact, during the World Columbian Exposition in 1893, more visitors explored the Chicago stockyards than any of the Exposition's other novel attractions. ${ }^{9}$

After the publication of Upton Sinclair's exposé, The Jungle, however, the fascination with this industrialized slaughter was gradually replaced by a collective distaste for the brutality of the meat processing industry. As Richard Bulliet describes in his book Hunters, Herders and Hamburgers: The Past and Future of Human-Animal Relationships, contemporary American society "continues to consume animal products in abundance, but psychologically, its members experience feelings of guilt, shame and disgust when they think (as seldom as possible) about the industrial processes by which domestic animals are rendered into products." ${ }^{\prime 10}$ To assuage our collective cultural guilt, the slaughterhouse was relocated, but not reformed. By the mid-1950s, spurred by advancements in refrigeration technology and the expansion of the interstate highway system, packinghouses were relocated to be closer to livestock producers.

As processing facilities industrialized, a shift also occurred from raising livestock in small numbers on geographically widespread medium-sized farms to producing livestock in much larger numbers on fewer farms known as Confined Animal Feeding Operations, or CAFOs. ${ }^{11}$ A CAFO is a regulated animal feeding facility that confines a large number of animals for more than 45 days in an area that does not produce vegetation during the growing season. Economies of scale, modern machinery, biotechnology, and global trade have encouraged the development of this highly efficient mode of production. The US Environmental Protection Agency classifies an operation as a CAFO if it houses more than any of the following number of animals: 1,000 cattle, 2,500 pigs, 10,000 piglets, 55,000 turkeys, 125,000 broiler chickens, or 82,000 laying hens. ${ }^{12}$

With so many resident animals, it is not uncommon for a single CAFO to generate the same amount of waste as a city of 100,000 people. ${ }^{13}$ The waste is often left untreated to sit in barns or large lagoons before being sprayed or spread on adjacent fields. Problems arise when the scale of massive production outstrips the ability for waste to be applied to and safely absorbed by the surrounding fields and farmland. Fields may be too wet or the surrounding area not large enough. Rain may wash manure from lagoons, piles and fields into ditches, creeks, and subterranean drainages, contaminating the watershed. In the United States, such waste has polluted 35,000 miles of rivers and has significantly contaminated groundwater in 17 states. ${ }^{14}$ According to the Pew Commission, over 1 million Americans are estimated to take their drinking water from such contaminated groundwater. ${ }^{15}$ 


\section{Amps}

As water transports toxic effluvia from CAFOs downstream, wind carries malodorous fumes to nearby communities. Though unpleasant odor may seem like little more than an annoyance, studies have shown that such malodors can have a profound impact on the health and quality life of those living in close proximity to industrial animal agriculture. ${ }^{16}$ Those residing near CAFOs experience increased frequency of wheezing and asthma, gastrointestinal distress, and impairment of salivary gland function during episodes of extreme malodor. ${ }^{17}$ Studies have also indicated that, even when odor is not noticeable, the fear of poor air quality can limit both social interactions and participation in outdoor leisure activities. ${ }^{18}$ Thus, CAFOs create public health concerns and can erode the social fabric of neighboring communities.

Sociological and anthropological research in meat-processing "boom-towns" such as Garden City, Kansas and Brooks, Alberta, Canada has shown that the negative effects of slaughterhouses and feedlots can often outweigh perceived economic benefits. Such effects include rapid shifts in demographics, increases in crime, and strains on local infrastructure, healthcare and other social services. ${ }^{19}$ That such facilities are disproportionally located in impoverished communities of color makes the physical and social consequences of this system even more problematic. ${ }^{20}$ The adverse side effects of CAFOs are exacerbated when neighboring communities have fewer economic resources, higher disease rates, limited access to healthy food, inadequate housing and lack of access to clean sources of potable groundwater. Comparatively low levels of academic attainment and limited political capital also make it extremely difficult for such communities to organize and advocate for environmental protection, regulation and enforcement. ${ }^{21}$ Thus, the siting and design of CAFOs have the potential to negatively impact ecosystems, public health, and social capital, particularly in rural communities that are already vulnerable.

Today, most urban livestock production and processing operations have been decommissioned. Unlike the grand buildings of the Union Stockyard Era, the architecture of the contemporary slaughterhouse is generic and placeless. Set back from the street and restricted from public access, the nondescript structures are designed to look like any other factory (Fig 2). Livestock confinement buildings for animal production have been designed in a similarly generic fashion (Fig 3). Whether they are nestled in the mountains of North Carolina or the expansive plains of Oklahoma, the massproduced, metal-skinned and mechanically ventilated structures look exactly the same. Such "designed indifference" has enabled the livestock industry to remain inconspicuous and largely unchallenged over the years. Meat processing has always been physically demanding, unpleasant and dangerous work, currently performed by a mostly immigrant labor force. ${ }^{22}$ There has been, however, a significant change in where this unsavory work occurs, rendering the process nearly invisible to the general public. 


\section{Amps}
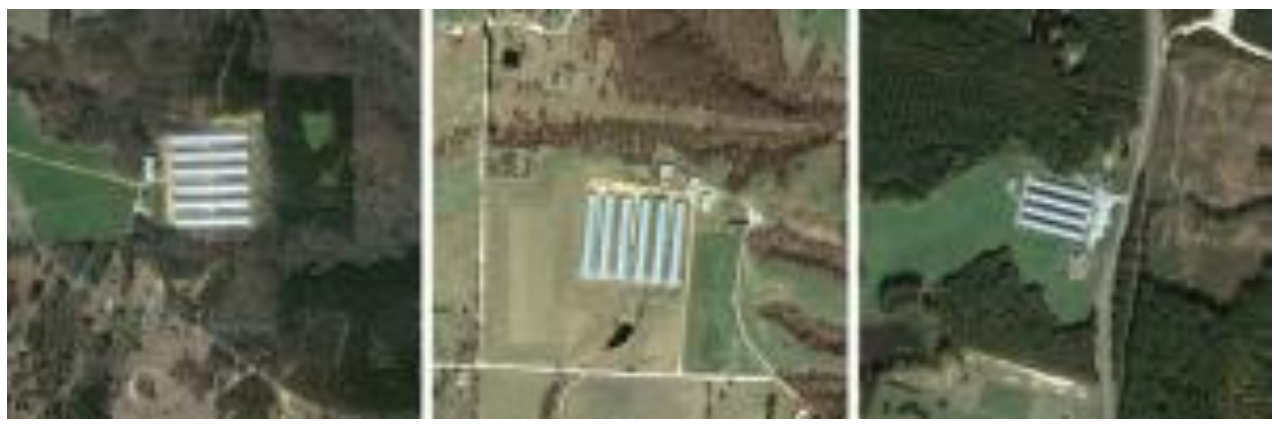

Figure 2. Aerial photographs of CAFOs demonstrate lack of geographic specificity. From left to right: poultry farms in Alabama, Arkansas and Virgina ${ }^{23}$

\section{Design Implications}

The challenges facing industrial animal production are by nature interdisciplinary. Though landscape architects and architects are uniquely positioned to facilitate collaboration and identify potential solutions, examples of such collaboration are limited. The bulk of applied design research, has surrounded the architecture of livestock facilities. The Center for Rural Design at the University of Minnesota is part of an interdisciplinary team currently developing integrated performance design guidelines for sustainable animal agriculture facilities. This research seeks to provide industry and allied communities with a metric for evaluating proposed locations, site and facility design, construction, and management of animal production facilities. ${ }^{24}$

Within the realm of design speculation, The Expanded Environment, formerly Animal Architecture, is a nonprofit organization advocating for the incorporation of biological and ecological agents into the built environment. Founder Edward Dodington advocates for a "cross-species design imperative" and has digitally published over 200 projects from architects, artists and designers that explore a wide range of animal-architectures. ${ }^{25}$ From agricultural theme parks to urban apiaries, these projects are mostly speculative in nature and intended primarily for a design audience. Though the majority of such projects have limited to no practical applications, the platform is useful in expanding the architectural field to include the consideration of spaces occupied by non-human animals.

Designers must engage with the landscape of meat production and processing in both practical and imaginative ways. If the realities of the system were rendered visible, society would be compelled to advocate for a more local, sustainable, transparent and humane model of meat production. This system need not be defined by society's collective nostalgia for a pastoral past and historic barnyard 


\section{Amps}

vernacular. Rather, design can define new models for contemporary animal agriculture that accepts the industry's importance in developing a sustainable and healthy food system to support the world's ever growing population. Architects could help develop new livestock facility design guidelines and create new architectural typologies that consume less energy, absorb hazardous gases and malodors, and mitigate the ecological and social consequences of the industry. ${ }^{26}$

At the site and planning scales, research indicates that site design and best management practices such as riparian buffers, engineered wetlands, grassed waterways, filter strips and field borders can significantly reduce sediment and nutrient loading in agricultural watersheds. ${ }^{27}$ Strategically designed shelterbelt systems near and within livestock facilities could mitigate malodor in adjacent communities. ${ }^{28}$ Rotational grazing strategies could protect soil quality, while creating valuable habitat for grassland species. ${ }^{29}$ Excess waste from confined feeding operations and processing byproducts could be used to support sustainable aqua and agricultural systems. ${ }^{30}$ Smaller, multi-species processing facilities distributed more evenly across livestock producing regions could encourage smallscale husbandry practices while improving quality of life for both animals and workers alike.

There exists no magic bullet, but such design opportunities could contribute to a more sustainable and humane system of meat production that benefits local communities and ecologies as well. However, the geography and design of the contemporary livestock industry leaves does little to encourage such change. Away from populated areas and hidden behind a generic façade, this industrial obscurity enables Americans to avoid confronting the collective moral dilemma of animal consumption.

\section{Rural Dumping Grounds}

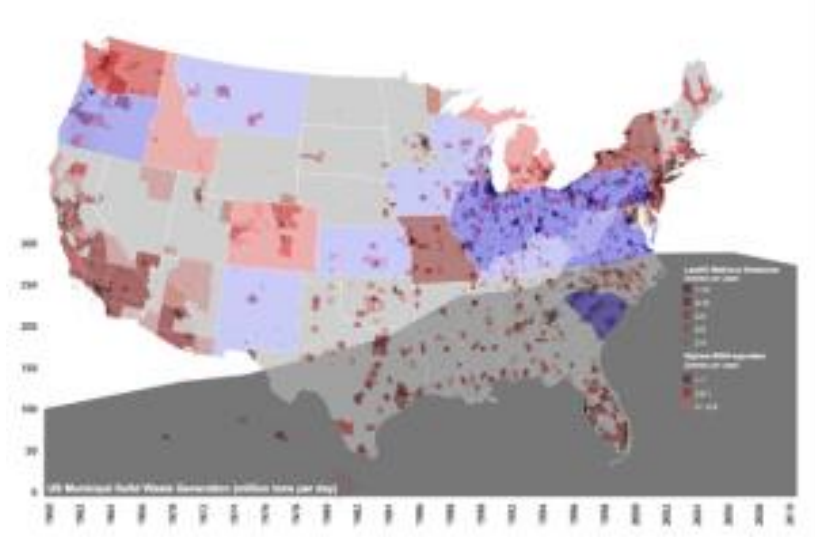

Figure 3. Mapping municipal solid waste generation, export, and emissions ${ }^{31}$ 


\section{Amps}

Just as livestock farms generate too much waste for nearby land, most American cities generate too much solid waste for local landfills. Beginning in the 1800 s, urban solid waste management was established as a local responsibility, with waste sent to local municipal dumps. As urban waste began to outpace the holding capacity of local landfills and the environmental consequences of waste disposal became apparent, legislation in the 1970s forced the closure of open urban dumps nationwide and required regional planning for municipal solid waste management. ${ }^{32}$ Today, the United States has a total of 1,908 active landfills: 128 are sited in the Northeast, 668 in the South, 394 in the Midwest, and 718 in the West. ${ }^{33}$ These landfills pollute the air, and when improperly designed, can contaminate the water table with toxic leachate. As an increasing amount of electronic waste enters landfills, this threat of groundwater contamination is increasing. ${ }^{34}$ Though the federal government established strict laws for the construction and maintenance of landfills, living in close proximity to landfills and waste transfer stations is associated with increased likelihood of disease. ${ }^{35}$ The adverse health effects near individual landfill sites can include low birth weight, birth defects, and certain types of cancers. ${ }^{36}$

With local urban communities unwilling to tolerate the noxious smells and environmental consequences of landfills, more urban trash is winding up in rural communities where political resistance is minimal. Taking into account tipping fees and land values, the economic advantages of waste export can be immense. Tipping fees vary widely according to the region, ranging from $\$ 11$ per ton in the Midwest and Southwest to more than $\$ 100$ per ton in the Northeast. ${ }^{37}$ With such an extreme price differential, states with higher tipping fees have a big incentive to transport their waste long distances. This leads to waste accumulating in rural states, where population density and average incomes are lower.

Exporting municipal solid waste (MSW) to less densely populated areas has become the norm for metropolitan regions like New York City. When the notorious Staten Island landfill Fresh Kills, which at one time was not only the largest landfill in the world but the largest man-made structure in the world, closed, the city of New York committed to exporting its trash to regional landfills. Each year, the city exports approximately 6 million tons of trash by truck and rail to landfills and incinerators in New Jersey, Ohio, Pennsylvania, Virginia and South Carolina. Trucks travel 40 million miles to dispose of New York City's waste alone. ${ }^{38}$ Such waste export raises numerous environmental and social justice concerns.

Today, twenty-five percent of all solid waste in the United States is transported across state lines. Trash is often transported hundreds of miles, by truck, rail and barge to privately owned, regional waste disposal facilities located in remote areas. ${ }^{39}$ These mega-landfills take advantage of economies 


\section{Amps}

of scale, storing high-volumes of waste on relatively small areas of land. The scale of such facilities can be staggering. Before it closed in 2013, La Puente Hills Landfill, outside of Los Angeles, received 130 million tons of garbage and was 40 stories tall, large enough to generate its own microclimate and wind-patterns. ${ }^{40}$ Reflecting the national out of sight, out of mind strategy, La Puente was replaced in 2013 by a much larger and more remote facility, Mesquite Regional Landfill, 200 miles southeast of Los Angeles in the Imperial Valley. ${ }^{41}$ Despite the fact that such facilities must install modern environmental protections, they will inevitably create future contamination problems. In addition, transporting MSW such long distances exacerbates this environmental damage by contributing to greenhouse gas emissions.

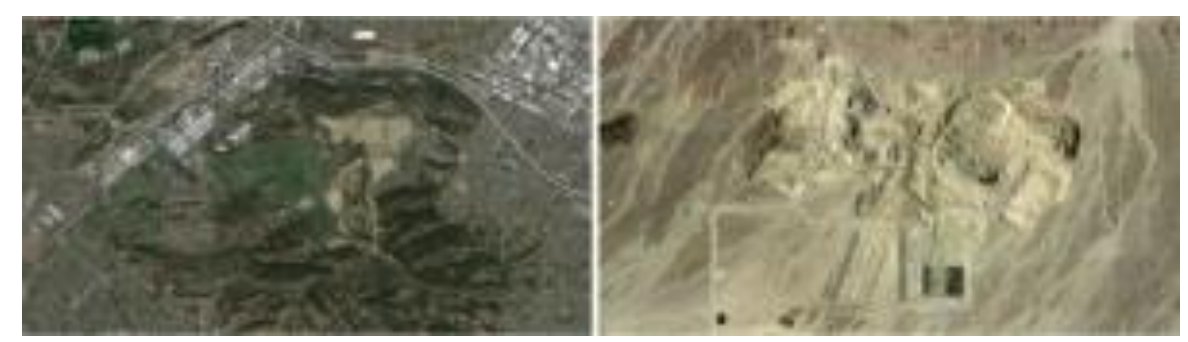

Figure 4. Los Angeles municipal waste previously sent to La Puente Hills Landfill (upper left), is now shipped 200 miles away to the newly opened Mesquite Regional Landfill (upper right) ${ }^{42}$

Transporting urban garbage to far away rural locations allows city dwellers to avoid confronting the consequences of excess waste. Urban populations push their waste into someone else's backyard, forcing those communities to deal with air pollution and groundwater contamination that is a consequence of affluent, consumptive lifestyles. Landfills are also often located in communities that are disproportionately rural and poor, whose residents do not have the agency to organize any opposition. $^{43}$

\section{Design implications}

Designers have engaged with the processes and products of waste in a variety of ways. In the context of design theory, landscape architect and professor at Massachusetts Institute of Technology, Alan Berger describes what he terms Drosscape in his book of the same name. He defines drosscapes as "large tracts of abused land on the peripheries of cities and beyond, where urban sprawl meets urban dereliction: landscapes of wasted land where the planners gave up. They are a world of contaminated former industrial sites, mineral workings, garbage dumps, container stores, polluted river banks, and sewage works." ${ }^{, 4} \mathrm{He}$ categorizes landfills as "waste landscapes of obsolescence" because they are designed explicitly to accommodate consumer waste. Though Berger identifies and describes the 


\section{Amps}

conditions of waste across the contemporary landscape in great detail, he offers little in the way of design solutions.

In praxis, landscape architects and engineers have been actively involved in the remediation and repurposing of decommissioned landfills. The social and ecological programming of Fresh Kills Park in Staten Island and La Vall d'en Joan in Barcelona, designed by Field Operations and Batlle i Roig, respectively, prove that the conversion of landfills to parks has great potential for cities and regional ecologies. Through innovative design and remediation, Fresh Kills Park, once the biggest landfill in the world, is now the largest park in New York City. The Park Masterplan includes nature preserves, animal habitats, hiking and bike paths, picnic areas, comfort stations, and many other amenities typical of a large public park. The plan also includes a dynamic ecological succession strategy in which birds and insects facilitate wetland restoration by dropping seeds and pollinating flowers. $^{45}$

While there is great merit in transforming inactive landfills into wildlife refuges and recreational spaces, such designs do not address the fact that Americans produce some 254 million tons of MSW annually. ${ }^{46}$ Even if large portions of the waste stream are diverted, recycled and reused, the country would still needs hundreds of landfills and incinerators distributed across the landscape. A speculative work by landscape architects Mira Engler and Gina Crandell provides a compelling example of how design and planning might begin to address this reality. The conceptual design for an “Open Waste System Park” features a decentralized network of suburban parks dedicated to waste recycling and management. Rather than hiding waste from the public, this design makes the spaces of waste disposal accessible and productive. ${ }^{47}$ As Engler notes in her essay, "Waste Landscapes: Permissible Metaphors in Landscape Architecture," "Instead of distancing ourselves from waste, design can bring people closer to waste operations and help foster creative solutions to problems intrinsic to waste disposal, issues common to all people."48

By re-conceptualizing waste as an opportunity, the relationship between urban waste generators and rural communities could be a positive one. A recycling and post-consumer manufacturing industry could bring much-needed jobs to rural areas, while compost facilities could provide organic compost for regional farms. Urban areas could adopt a proximity principle that mandates that waste be treated and/or disposed of as close as possible to the point of origin. ${ }^{49}$ Urban communities would quickly demand the design and development of cleaner, more sustainable landfills. Such design strategies would allow society to confront the real problem: Americans create too much waste. With the consequences of waste left hidden in far away landfills, however, little remains to incentivize urban communities to place more value on recycling, re-using, composting, and manufacturing goods that are built to last. 


\section{Amps}

\section{Rural Prisons}

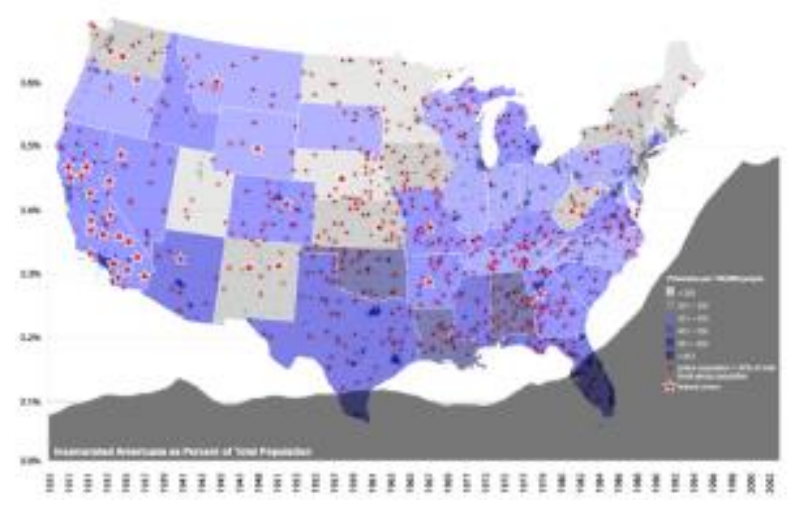

Figure 5. Mapping inmate density ${ }^{50}$

The rural communities that import urban trash are often the same communities that compete for prisons, each a culturally unappealing and non-productive industry that requires large tracts of land. Since 1980, the majority of new prisons have been built in non-metropolitan areas, and as a result, the majority of predominately urban prisoners are now housed in rural America. In fact, in the United States today, prisoners outnumber small family farm owners. While the Census of Agriculture estimated that 2,131,007 family farms operated in $2009,{ }^{51}$ the U.S. Bureau of Justice Statistics estimated that 2,266,800 adults were incarcerated in U.S. federal and state prisons and county jails in $2011 .^{52}$ During the last three decades, rising incarceration rates coupled with the decline of rural economies have resulted in prisons emerging as a "growth industry" in rural America. ${ }^{53}$

The majority of prisons constructed since the 1990s have been concentrated in the economically depressed regions of the Southern United States. On the western plains of Texas, where both agriculture and oil extraction were on the decline, eleven rural counties opened new prisons. Overall, one in every five new rural prisons opened during the 1990s opened in Texas, with a total of forty-nine new facilities. Approximately 12 new prisons each were opened in the Mississippi Delta and Southern Coal Fields regions of Appalachia, with south central Georgia opening fourteen new rural prisons. ${ }^{54}$ All in all, about 350 counties across the United States have acquired new rural prisons since the prison boom began. These new facilities incarcerated about 235,000 inmates and employed 75,000 workers at the end of the 1990 s - averaging 30 new jobs for every 100 prisoners. ${ }^{55}$

The promise of a stable growth economy in which every ten inmates brings three new jobs has started a bidding war between small towns competing to host new state prisons. The prison site 


\section{Amps}

selection process is the result of a complex interchange between local and state officials. Towns selected for prison sitings are typically chosen because they meet infrastructural requirements (e.g. proximity to highways, sewer and water accessibility) and they offer land for a competitively low price. This has led many towns to take out loans in order to upgrade their infrastructure and to sell their land for far below market value. Antwerp, a small community in upstate New York, applied for a $\$ 600,000$ federal grant to rebuild their water supply system to increase their chances of winning a state prison. Pennsylvania offered to sell 200 acres of prime state-owned farmland in rural Wayne County to the Federal Bureau of Prisons (FBOP) for just a dollar. ${ }^{56}$

The rural communities vying for new prisons are typically characterized by endemic poverty and limited economic growth. Though rural and predominately white, these towns have a great deal in common with the impoverished and diverse urban spaces from which the majority of prisoners originate. As Anne Bonds notes in an essay on prison sitings and poverty, "Depressed rural communities have been dispossessed by similar sorts of processes, (re)producing disinvestment, unemployment, and entrenched poverty across urban and rural spaces. But prisons do not solve poverty in either place. ${ }^{, 57}$ As local governments invest in infrastructure and offer tax breaks and cheap land to compete for new corrections facilities, limited resources are funneled away from public welfare and social infrastructure in rural areas.

Regrettably, the promise of economic growth as a result of the prison industry has remained largely unfulfilled in rural America. Research on the prison boom indicates that, when compared to non-prison towns, new state prison communities experience less growth and see increased levels of unemployment and poverty. ${ }^{58}$ This results from the fact that prisons do not depend on adjacent small towns for the vast majority of their inputs, including employees. The majority of prison jobs go to commuters from other towns who are better qualified than members of the host community. Upper level management and correctional officer jobs often come with educational and experience requirements that local rural residents simply do not have. Thus, new prisons are frequently filled with large numbers of veteran correctional personnel from other facilities. Moreover, studies have indicated that the distances prison employees have to commute is, in the majority of instances, nearly double the average commuter time. ${ }^{59}$ Ultimately, fewer than twenty percent of new jobs go to current residents of new prison towns and thus the prison industry fails to create significant economic bonds with its host community. ${ }^{60}$

Though the economic benefits of a new prison can be minimal, the adverse infrastructural, ecological and cultural consequences of its siting and operation are myriad. Since prison employees often commute long distances, traffic during the typical three shift changes can congest local roads. Bright security lighting creates light pollution that, in addition to impacting the beauty of the night sky, 


\section{Amps}

has been shown to significantly interfere with bird migrations and other animal behaviors. ${ }^{61}$ When new prisons dominate a community's economic, social, and political landscape, they can also erode its cultural identity and sense of place over time. Richard Purdue, former mayor of Ossining, New York, a prison town that changed its name from Sing Sing in order to minimize the negative perceptions of the town, witnessed this process first hand. In a letter written in response to New York's proposal to site a maximum security prison in the small Adirondack town, Purdue states "A state prison is a disadvantage to a small community. A maximum security prison in particular drags on the public perception of the town and quietly injures a town's perception of itself."62

Perhaps the most disturbing consequence of the rural isolation of the prison system, however, is the reshaping of the political landscape. Prison inmates are counted as residents of the communities in which they are incarcerated. The incarcerated population of about 2 million is larger than that in each of the 15 smallest states and would have five votes in the Electoral College if it comprised a single state and inmates were allowed to vote. ${ }^{63}$ Thus, even though they cannot vote, the country's some two million inmates figure heavily in the redrawing of political boundaries. Higher population results in more political representation, and often more money for schools, infrastructure, and other government services. In Coxsackie, New York, for example, prisoners have allowed the community to receive federal antipoverty funds. Because they do not earn income, prisoners in the town's two correctional facilities (who made up nearly thirty percent of the town's population in 1990) drove down the median income on the census and made Coxsackie eligible to receive federal funding. ${ }^{64}$ The votes of these disenfranchised prisoners are effectively surrendered to neighboring residents, thus shifting political and economic power away from the predominately minority, urban prison population and giving it to the mostly white, rural regions.

\section{Design Implications}

Designers have engaged with the problem of incarceration in varying ways. That architecture has been the primary form of design investigation is not surprising, given that confined architecture is the primary method of imprisonment. From the haunting imaginary prisons of Giovanni Battista Piranesi to the circular surveillance design of Jeremy's Bentham's Panopticon, imprisonment has captivated the architectural imagination for centuries. ${ }^{65}$

Contemporary examples of innovative prison design are located primarily in Europe. The Halden Prison in Halden, Norway by HLM arkitektur in collaboration with Erik Møller Arkitekter is considered to be the world's most humane prison. Norway's second largest prison, with a capacity of 252 inmates, opened in April of 2010. With exteriors made of bricks, galvanized steel, and larch, the building responds to the local woodland landscape. Trees obscure the twenty foot security wall, so that 


\section{Amps}

the architecture appears less hostile. Halden also features jogging trails in nearby woods and a freestanding two-bedroom house where inmates can host their families during overnight visits. The design reflects the principles of the Norwegian penal system: that treating prisoners humanely improves their chances of becoming productive members of society. ${ }^{66}$

Though the Halden prison is an example how design can improve quality of life for inmates and guards, it does not fundamentally challenge the justice system. The design activist group, Architects / Designers / Planner for Social Responsibility (ADPSP), on the other hand, would like to abolish incarceration altogether. Led by architect Raphael Sperry, the Prison Alternatives Initiative calls on architects and other design professionals to refuse to design prisons and instead support community-based alternatives to incarceration. ${ }^{67}$ ADPSP is also asking the American Institute of Architects to change their Code of Ethics and Professional Conduct to "prohibit the design of spaces for killing, torture, and cruel, inhuman or degrading treatment." ${ }^{68}$ With an increasingly vocal contingent advocating that architects remove themselves from prison design entirely, contemporary designers in America are understandably reluctant to be associated with the process of incarceration. As a result, new prison design and construction is carried out by a small number of large and relatively anonymous firms. This anonymity discourages architectural innovation and perpetuates generic, placeless design. Moreover, the displacement of prisons to rural areas further eliminates the need for a mediated and designed public presence. Prison architecture is not an icon of civic pride or communal justice because no one is supposed to see it.

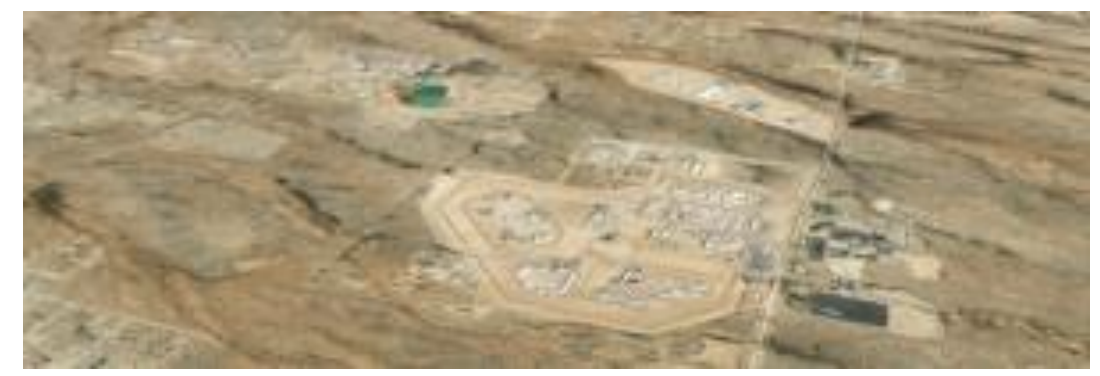

Figure 6. The spatial buffering and geographic isolation of Arizona State Prison, outside of Tuscon is characteristic of rural prison design today ${ }^{69}$

With bland nondescript facades surrounded by razor wire and high walls, prisons are commonly surrounded by a substantial spatial buffer that separates the prison population from society at large. Prison facilities are thus isolated from both the urban communities that supply the inmates and the rural communities in which they are sited. The geographic and architectural concealment of prisons belies the fact that there are over two million incarcerated people in the United States today. If the 


\section{Amps}

entire inmate population resided in a single metropolitan area, it would comprise the fourth-largest city in the United States, having more inhabitants than Houston. ${ }^{70}$ The concealment of such an immense population allows the special interest groups that are profiting from the prison industry to grow their businesses while most of the American population remains unaware of what is transpiring in remote regions of the United States. This paradigm of spatial secrecy is not immutable, however.

Designers and planners should advocate for the re-urbanization of incarceration. The proximity of prisons to urban centers would facilitate family visits, which are known to contribute to the psychological well-being of the inmates and reduce recidivism. ${ }^{71}$ Inmates would also be better prepared for reintegration into their home communities through the use of visits and furloughs. Access to legal, social and medical services would also be facilitated by the relocating of prisons into metropolitan areas. Cities would provide a more diverse, well trained staff that could more closely represent the racial and cultural backgrounds of the inmate populations. Most importantly, by removing landscape barriers and developing new urban architectural typologies that reflect collective ideals of communal justice, designers could help uncover the realities of incarceration and, in so doing, encourage society to enact change.

\section{Conclusion}

We seldom think about where our trash goes, how animals are slaughtered for meat, or what happens to the 2.3 million Americans locked behind prison walls. This is no oversight - it is designed. The remote siting and placeless design of livestock operations, waste management systems, and prison complexes allow society to avoid confronting the unsettling nature of wastefulness, slaughter, and imprisonment. From water contamination to increased crime, the environmental and social consequences of such designed indifference can be wide ranging. Hidden from public view, the ecologically and socially damaging nature of these industries will remain unchallenged. Though design has facilitated the paradigm of industrial obscurity, it can also help to change it.

The complexity of urban-rural relationships requires research and management approaches that cross traditional disciplinary lines. We have in the past addressed the challenges of the city and countryside as separate and closed systems. This has had limited success in mitigating urban-rural conflicts. Planning and management decisions for relocating undesirable land uses outside of urban areas cannot be made outside the context of rural needs and wishes. Rural and urban landscapes must be acknowledged as mutually interdependent and equally important parts of a unified whole. Architects and Landscape Architects are uniquely positioned to employ a systems approach and develop scenarios, typologies, and generative spatial principles that reconcile rural resources with urban demands. As economic, social, urban, and environmental generalists, designers can bring 


\section{Amps}

perspective and vision to these issues. A broad macro-level knowledge base combined with site and architectural scale expertise, affords them a unique ability to intertwine scientific, visual and verbal thought across scales and communicate across disciplines.

With considered design and participatory planning, ecologically and socially damaging urban industries could potentially be transformed into assets for rural communities. Expanded free range and sustainable husbandry methods, coupled with small scale processing and distribution networks, could improve the quality of life for both the animals and the people responsible for their slaughter.

Recycling and post-consumer manufacturing enterprises could help to enliven stagnating rural economies. Urban food and yard waste could be composted and used as fertilizer in a new model of nutrient efficient agriculture. A new prison typology that allows the public to see beyond its walls, figuratively if not literally, might force society to reexamine the racially and culturally complex realities of incarceration. Though far from comprehensive, these potential solutions should be a springboard for further design investigation.

The time has come to identify synergies and strategies hidden within existing urban-rural relationships. Contemporary academic urbanisms tend to homogenize local space and identity, defining the rural landscape as ecological repository, industrial staging ground, or urban hinterland. In contrast, preservation frequently addresses rural place-making at the neighborhood and architectural scale, while ignoring regional ecologies and industries. Design must adopt a synthetic approach to rural and urban territories whereby ecological and agro-industrial production supports rather than suppresses the identity, integrity and prosperity of local communities. In so doing, designers can contribute to a more sustainable, humane, and fair future for rural and urban communities alike.

\footnotetext{
${ }^{1}$ Ebenezer Howard, and Frederic J. Osborn. Garden Cities of To-morrow. Cambridge, Mass.: M.I.T. Press, 1965.

${ }^{2}$ Patrick Geddes was among the first urban theorists to suggest that human settlement ought to be analyzed in the context of its natural region. Patrick Geddes, Cities in Evolution; an Introduction to the Town Planning Movement and to the Study of Civics (New York: H. Fertig, 1968)

${ }^{3}$ Ian L McHarg. Design with Nature. (New York: Natural History Press, 1969)

${ }^{4}$ For the purpose of the study, "rural and urban" shall adhere to the definitions established by the Federal Register Notice for 2010 United States Census. To qualify as an urban area, the territory identified according to criteria must encompass at least 2,500 people, at least 1,500 of which reside outside institutional group quarters. "Rural" is defined as any population, housing, or territory outside urban areas. "Urban Area Criteria for the 2010 Census; Notice," 76 Federal Register 164 (24 August 2011), 53030-53031.

${ }^{5}$ Rural America at a Glance: 2013 Edition. (Washington, D.C.: U.S. Dept. of Agriculture, Economic Research Service, 2013) ${ }^{6}$ Ibid

${ }^{7}$ Potential Priority Water Resource Subregions U.S. Department of Agriculture Natural Resources Conservation Service, 2000 and 2007 Census of Agriculture, U.S. Department of Agriculture National Agricultural Statistics Service, 2007.

${ }^{8}$ J'Nell Pate, America's Historic Stockyards: Livestock Hotels (Fort Worth, Tex.: TCU Press, 2005)

${ }^{9}$ Dorothee Brantz, "Recollecting the Slaughterhouse" Cabinet, A Quarterly Magazine of Art and Culture (2001): 118

${ }^{10}$ Richard Bulliet, Hunters, Herders and Hamburgers: the Past and Future of Human Animal Relationships, (New York: Columbia University Press, 2003), 3.

${ }^{11}$ Daniel Imhoff. The CAFO Reader: The Tragedy of Industrial Animal Factories. (Los Angeles:
} 
Foundation for Deep Ecology, 2010). xiii

${ }^{12}$ United States Environmental Protection Agency, "CAFO NPDES Regulations and Effluent Limitations Guidelines and Standards," Federal Register /Vol. 73, No. 225 (2008).

${ }^{13}$ Imhoff,The CAFO Reader, xv.

${ }^{14}$ USDA. Natural Resources Conservation and U.S. EPA, as cited in Imhoff, The CAFO Reader, 43.

15 "Putting Meat on the Table: Industrial Farm Animal Production in America," Pew Commission on Industrial Animal Farm

Production, (2008) accessed October 16, 2013 http://www.pewtrusts.org/Reports/Industrial_Agriculture/PCIFAP_FINAL.pdf.

${ }^{16}$ Carrie Hribar "Understanding Concentrated Animal Feeding Operations and Their Impact on Communities" National

Association of Local Boards of Health (2010), 7

${ }^{17}$ Steve Wing et al "Air Pollution and Odor in Communities Near Industrial Swine Operations" Environmental Health

Perspectives Vol 116, No 10 (2008): 1362-1367

${ }^{18} \mathrm{M}$. Tajik et al "Impact of odor from industrial hog operations on daily living activities" NEW SOLUTIONS A Journal of Environmental and Occupational Health Policy 18 (2008):195-205.

${ }^{19}$ Amy Fitzgerald, "A Social History of the Slaughterhouse: From Inception to Contemporary Implications," Research in Human Ecology Vol.17, No. 1(2010): 58-69.

${ }^{20}$ An example of such environmental injustice can been seen in North Carolina where hog CAFOs are clustered low-income, minority communities. Wendee Nicole, CAFOs and Environmental Justice: The Case of North Carolina, 121 Envtl. Health Perspectives (2013), A183.

${ }^{21}$ Bob Edwards and Anthony Ladd "Environmental Justice, Swine Production and Farm Loss in North Carolina" Sociological Spectrum. 20 (2000): 263-290.

${ }^{22}$ Georgeanne Artz, Rebecca Jackson, and Peter F. Orazem, "Is It a Jungle Out There? Meat Packing, Immigrants, and Rural Communities" Journal of Agricultural and Resource Economics 300 (August 2010), 299.

${ }^{23}$ Google Earth, Accessed October 10, 2014

${ }^{24}$ Dewey Thorbeck. Rural design: a new design discipline. (Abingdon, Oxon: Routledge, 2008), 8.

${ }^{25}$ Edward Dodington. "The Cross-Species Design Imperative," The Expanded Environment, accessed August 10, 2014 http://www.expandedenvironment.org/cross-species-imperative/

${ }^{26}$ Thorbeck, 199.

${ }^{27}$ Kellie B. Vaché, Joseph M. Eilers and Mary V. Santelmann, "Water Quality Modeling Of Alternative Agricultural Scenarios In The U.S. Corn Belt," Journal of the American Water Resources Association, 38: 3 (June 2002 ), 773.

${ }^{28}$ Research indicates that shelterbelts, when planted in strategic designs (e.g. on-farm location, species selection), can help incrementally to reduce odor pollution. John Tyndall and Joe Colletti "Mitigating swine odor with strategically designed shelterbelt systems: a review” Agroforestry Systsems 69 (2007), 61.

${ }^{29}$ Jerry L. Holechek, Raul Valdez, Sanford D. Schemnitz, Rex D. Pieper and Charles A. Davis. "Manipulation of Grazing to Improve or Maintain Wildlife Habitat” Wildlife Society Bulletin, 10: 3 (Autumn, 1982), 209.

${ }^{30}$ Peter Edwards, "A review of recycling organic wastes into fish, with emphasis on the tropics." Aquaculture 21:3 (1980), 261.

${ }^{31}$ Environmental Industry Association and U.S. Environmental Protection Agency, Landfill Methane Outreach Program (LMOP), April 2008.

${ }^{32}$ Garrick E. Louis “A Historical Context of Municipal Solid Waste Management in the United States" Waste Management and Research. 22 (2004), 306.

33 "The State of Garbage in America," BioCycle, (2010), accessed December 15, 2013

http://www.biocycle.net/images/art/1010/bc101016_s.pdf

${ }^{34}$ The E.P.A. estimates that 2.6 million tons of electronic waste were landfilled in 2007. Such waste leaches poisons and heavy metals into surrounding soil and groundwater. Leslie Kaufman, "A Green Way to Dump Low Tech Electronics" The New York Times. N.p. (30 June 2009) accessed October 10, 2014.

${ }^{35}$ This risk applies to both landfills and waste transfer stations. A comparative study of health risks of waste management strategies conducted by Columbia University researchers indicated that the health risks of landfilling is five times greater than waste-to-energy incineration. Pearl Moy et. al,“Options for management of municipal solid waste in New York City: A preliminary comparison of health risks and policy implications" Journal of Environmental Management 87.1 (2008): 73.

${ }^{36}$ Martine Vrijiheid, "Health effects of residence near hazardous waste landfill sites: a review of epidemiologic literature," Environmental Health Perspectives 108 (2000): 101-112.

${ }^{37}$ Kristin Engel, "Reconsidering the National Market in Sold Waste: Trade-offs in Equity, Efficiency, Environmental Protection, and State Autonomy," North Carolina Law Review 73 (1995).

38 "Taxes In, Garbage Out :The Need for Better Solid Waste Disposal Policies in New York City," Citizens Budget Commission 29

${ }^{39}$ Vivian Thompson, Garbage In, Garbage Out: Solving the Problems with Long-Distance Trash Transport (University of Virginia Press, 2009). Ebook accessed July 1, 2014

${ }^{40}$ Geogh Manaugh and Nicola Twilley. "Mount Angeles” Venue, (2013), accessed July 15, 2013 http://v-e-n-u-e.com/MountAngeles

41 Ibid.

${ }^{42}$ Google Earth, Accessed October 10, 2014 


\section{Amps}

${ }^{43}$ Robert Bullard, Dumping In Dixie: Race, Class, and Environmental Quality (Boulder, CO: Westview Press, 2000), 1-24.

${ }^{44}$ Alan Berger. Drosscape: Wasting Land in Urban America. (New York: Princeton Architectural Press, 2006).

${ }^{45}$ Field Operations. 2002. "Fresh Kills Competition." Praxis 4 : 18-27.

46 "Municipal Solid Waste Generation, Recycling and Disposal in the United States: Facts and Figures for 2012" U.S.

Environmental Protection Agency (2012) accessed October 10, 2014

http://www.epa.gov/osw/nonhaz/municipal/pubs/2012_msw_fs.pdf

${ }^{4 T}$ Mira Engler, Designing America's Waste Landscapes (Baltimore: Johns Hopkins University Press, 2004), $173-174$.

${ }^{48}$ Mira Engler, "Waste Landcsapes: Permissible Metaphors in Landscape Architecture” Landscape Journal 14: 1 (1995), 24.

49 The Proximity Principal is emphasized in the European Union in order to confer proportionally more responsibilities to the communities that create waste. Waste Treatment and Disposal, (Chichester, UK: Wiley \& Sons, Ltd 2005), 8 - 13.

${ }^{50}$ United States Bureau of Justice Statistics, 2009.

${ }^{51}$ A family farm is defined as an operation grossing less than $\$ 250,000$ annually. "Agriculture: Section 17" Statistical Abstract of the United States (2012) accessed October 10, 2014

http://www.census.gov/compendia/statab/cats/agriculture.html

${ }_{52}$ Correctional Population in the United States, 2011. Bureau of Justice Statistics. Retrieved 10 February 2012

${ }^{53}$ Jeanie Thies. "Prisons and Host Communities: Debunking the Myths and Building Community Relations," Corrections Today 62: 2 (2000), 136-139.

${ }^{54}$ Tracy Huling. "Building a Prison Economy in Rural America," In Mauer, M. \& Chesney-Lind, M. (Eds.) Invisible

Punishment: The Collateral Consequences of Mass Imprisonment (New York: The New Press, 2002), 197-213.

55 Ibid, 198

${ }^{56}$ Ibid, 198

${ }^{57}$ Ann Bonds "Building Prisons, Building Poverty: Prison Sitings, Dispossession, and Mass Incarceration" in Beyond Walls and Cages: Prisons, Borders, and Global Crisis, ed. Jenn M. Lloyd et al (Atlanta: University of Georgia Press, 2012).

${ }^{58}$ Terry L. Besser and Margaret M. Hanson, "The Development of Last Resort: The Impact of New State Prisons on Small Town Economies," Journal of the Community Development Society 35 (2004): 1-16, accessed October 16, 2013, doi: $10.1080 / 15575330409490129$.

${ }^{59}$ Ruth Wilson Gilmore. Golden gulag: prisons, surplus, crisis, and opposition in globalizing California. (Berkeley: University of California Press, 2007).

${ }^{60}$ Ibid.

${ }^{61}$ Joe Bower, "The Dark Side of Light." Audubon (March-April 2000) accessed October 10, 2014

http://archive.audubonmagazine.org/darksideoflight.html

${ }^{62}$ Richard Purdue, quoted in Tracy Huling, "Building a Prison Economy in Rural America," in Invisible punishment: the collateral consequences of mass imprisonment, ed. Meda Chesney-Lind et al. (New York: New Press, 2002).

${ }^{63}$ David Hamsher, Comment, "Counted Out Twice_-Power, Representation, and the "Usual Residence Rule" in The Enumeration of Prisoners: A State-Based Approach to Correcting Flawed Census Data" Journal of Criminal Law and Criminology Vol. 96, No 1 (2005):299-328.

${ }^{64}$ Huling, 2009.

${ }^{65}$ Norman Bruce Johnston, Forms of constraint: a history of prison architecture. (Urbana: University of Illinois Press, 2000).

${ }^{66}$ William Lee Adams "Norway Builds the World's Most Humane Prison” Time (May 10, 2010) accessed October 10, 2014 http://content.time.com/time/magazine/article/0,9171,1986002,00.html

бт "Prison Alternatives Initiative" Architects / Designers / Planner for Social Responsibility Accessed October 10, 2014 http://adpsr.org/home/prison_alternatives_initiative1 ${ }^{68}$ Ibid.

${ }^{69}$ Google Earth, Accessed October 10, 2014

${ }^{70}$ The US Census Bureau estimated that Houston has a population of 2.196 million, while the U.S. Bureau of Justice Statistics estimated that 2,266,800 adults were incarcerated in U.S. federal and state prisons, and county jails in 2011

71 William D. Bales "Inmate Social Ties and the Transition to Society: Does Visitation Reduce Recidivism?" Journal of Research in Crime and Delinquency 45: 287 (2008), 287. 


\section{Amps}

\section{Bibliography}

Bales, William D. "Inmate Social Ties and the Transition to Society: Does Visitation Reduce Recidivism?" Journal of Research in Crime and Delinquency 45: 287 (2008), 287-321.

Berger, Alan. Drosscape: Wasting Land in Urban America. (New York: Princeton Architectural Press, 2006).

Besser, Terry L. and Margaret M. Hanson, "The Development of Last Resort: The Impact of New State Prisons on Small Town Economies," Journal of the Community Development Society 35 (2004): 1-16, accessed October 16, 2013, doi: 10.1080/15575330409490129.

Bonds, Ann. "Building Prisons, Building Poverty: Prison Sitings, Dispossession, and Mass Incarceration" in Beyond Walls and Cages: Prisons, Borders, and Global Crisis, ed. Jenn M. Lloyd et al (Atlanta: University of Georgia Press, 2012).

Brantz, Dorothee, "Recollecting the Slaughterhouse" Cabinet, A Quarterly Magazine of Art and Culture (2001): 118-23.

Bullard, Robert. Dumping In Dixie: Race, Class, and Environmental Quality (Boulder, CO: Westview Press, 2000),

Bulliet, Richard. Hunters, Herders and Hamburgers: the Past and Future of Human Animal Relationships, (New York: Columbia University Press, 2003).

Dodington, Edward. "The Cross-Species Design Imperative," The Expanded Environment, accessed August 10, 2014 http://www.expandedenvironment.org/cross-species-imperative/

Edwards, Bob and Anthony Ladd "Environmental Justice, Swine Production and Farm Loss in North Carolina" Sociological Spectrum. 20 (2000): 263-290.

Engel, Kristin. "Reconsidering the National Market in Solid Waste: Trade-offs in Equity, Efficiency, Environmental Protection, and State Autonomy," North Carolina Law Review 73 (1995), 1481-1566.

Engler, Mira. Designing America's Waste Landscapes (Baltimore: Johns Hopkins University Press, 2004),

Engler, Mira. "Waste Landcsapes: Permissible Metaphors in Landscape Architecture" Landscape Journal 14: 1 (1995), 11-25.

Fitzgerald, Amy. "A Social History of the Slaughterhouse: From Inception to Contemporary Implications," Research in Human Ecology Vol.17, No. 1(2010): 58-69.

Geddes, Patrick . Cities in Evolution; an Introduction to the Town Planning Movement and to the Study of Civics (New York: H. Fertig, 1968)

Gilmore, Ruth Wilson. Golden gulag: prisons, surplus, crisis, and opposition in globalizing California. (Berkeley: University of California Press, 2007).

Hamsher, David. Comment, "Counted Out Twice-Power, Representation, and the "Usual Residence Rule" in The Enumeration of Prisoners: A State-Based Approach to Correcting Flawed Census Data" Journal of Criminal Law and Criminology Vol. 96, No 1 (2005):299-328

Huling, Tracy. "Building a Prison Economy in Rural America," in Invisible punishment: the collateral consequences of mass imprisonment, ed. Meda Chesney-Lind et al. (New York: New Press, 2002). 197-213

Imhoff. Daniel. The CAFO Reader: The Tragedy of Industrial Animal Factories. (Los Angeles: Foundation for Deep Ecology, 2010).

Johnston, Norman Bruce. Forms of constraint: a history of prison architecture. (Urbana: University of Illinois Press, 2000).

Louis, Garrick E. "A Historical Context of Municipal Solid Waste Management in the United States" Waste Management and Research. 22 (2004), 306-322.

Manaugh, Geoff and Nicola Twilley. "Mount Angeles" Venue, (2013), accessed July 15, 2013 http://ve-n-u-e.com/Mount-Angeles

McHarg. Ian L. Design with Nature. (New York: Natural History Press, 1969) 
Moy, Pearl et. al,“Options for management of municipal solid waste in New York City: A preliminary comparison of health risks and policy implications" Journal of Environmental Management 87.1 (2008): 73-79.

"Putting Meat on the Table: Industrial Farm Animal Production in America," Pew Commission on Industrial Animal Farm Production, (2008) accessed October 16, 2013 http://www.pewtrusts.org/Reports/Industrial_Agriculture/PCIFAP_FINAL.pdf.

"The State of Garbage in America," BioCycle, (2010), accessed December 15, 2013 http://www.biocycle.net/images/art/1010/bc101016 s.pdf

Tajik, M. et al. "Impact of odor from industrial hog operations on daily living activities" $N E W$ SOLUTIONS A Journal of Environmental and Occupational Health Policy 18 (2008):195-205.

"Taxes In, Garbage Out :The Need for Better Solid Waste Disposal Policies in New York City," Citizens Budget Commission 29

Thies, Jeanie. "Prisons and Host Communities: Debunking the Myths and Building Community Relations," Corrections Today 62: 2 (2000), 136-139.

Thompson, Vivian. Garbage In, Garbage Out: Solving the Problems with Long-Distance Trash Transport (University of Virginia Press, 2009). Ebook accessed July 1, 2014

Thorbeck, Dewey. Rural design: a new design discipline. (Abingdon, Oxon: Routledge, 2008).

Vrijiheid, Martine. "Health effects of residence near hazardous waste landfill sites: a review of epidemiologic literature," Environmental Health Perspectives 108 (2000): 101-112.

Wing, Steve et al "Air Pollution and Odor in Communities Near Industrial Swine Operations" Environmental Health Perspectives Vol 116, No 10 (2008): 1362-1367. 